\title{
ESPACIALIZAÇÃO DA AGROPECUÁRIA NO MUNICÍPIO DE PRESIDENTE FIGUEIREDO - AMAZONAS
}

\author{
João Carlos Ferreira Júnior ${ }^{(a)}$, Flávio Wachholz ${ }^{(\mathrm{b})}$ \\ (a) Licenciado em Geografia e Mestrando em Gestão e Regulação de Recursos Hídricos (ProfÁgua), Escola \\ Normal Superior, Universidade do Estado do Amazonas, jcfj23@gmail.com \\ (b) Professor Adjunto e Coordenador do Curso de Licenciatura em Geografia e Professor do Mestrado em Gestão \\ e Regulação de Recursos Hídricos (ProfÁgua), Escola Normal Superior, Universidade do Estado do Amazonas, \\ fwalemao@gmail.com
}

Eixo: Uso e ocupação das terras e legislação ambiental

\begin{abstract}
Resumo
A agropecuária é um dos principais agentes modificadores do espaço, influenciando na dinâmica do uso da terra em diferentes escalas e intensidades. Este trabalho tem por objetivo compreender a espacialização da agropecuária no município de Presidente Figueiredo. Para isso foram realizados levantamentos de dados espaciais da agropecuária, trabalhos de campo e mapeamento de uso da terra, a partir de imagens Landsat $5 \mathrm{TM}$. Com isso, foi possível comprovar que a produção agropecuária se encontra concentrada, principalmente, ao longo da rede viária, BR-174, AM-240 e das vicinais, fruto da produção dos assentamentos agrícolas, das comunidades rurais e da agroindústria. A pastagem é classe com maior representatividade de área, com 20.417 hectares. Estudos sobre o uso da terra são de grande importância para conhecer a espacialidade dos usos do espaço, contribuindo para planejamentos futuros de políticas públicas voltadas para setor rural.
\end{abstract}

Palavras chave: Uso da terra; Landsat 5 TM; Sensoriamento remoto; Amazônia.

\section{Introdução}

A agropecuária é dos principais modificadores da paisagem rural no Brasil e na Amazônia. No ano de 2006, segundo o IBGE (2009), os estabelecimentos agropecuários ocupavam uma área total de 329,9 milhões de hectares, correspondendo a 38,7\% do território brasileiro. Na Amazônia o avanço da agropecuária ocorre de forma acelerada, sendo vista atualmente como a fronteira a ser superada pelos grandes agricultores, pecuaristas, mineradores e madeireiros, estas áreas possuem um padrão de ocupação já consolidado, conhecida como o "arco de desmatamento" (SAITO, 2011).

No Amazonas, o desmatamento de novas áreas, em decorrência da dinâmica agropecuária, ocorre com maior intensidade na porção sul do estado, principalmente ao longo das rodovias BR-230 (Transamazônica) e BR-319, próximo ao limite com os estados do Acre e de Rondônia. Contudo, a agropecuária também se faz presente em outros municípios do interior e da Região Metropolitana de Manaus (RMM), à qual o munícipio de Presidente Figueiredo está inserido, este sendo fruto de um "novo" padrão de ocupação, atrelado as conexões ao longo das estradas, que contribuíram para redução do tempo e das distâncias das viagens na região (BECKER, 2001 apud SAITO, 2011).

Com grande importância para o entendimento da espacialidade do município, foi a partir da construção da BR-174 (1970-1977) que se criou o município de Presidente Figueiredo (1981), além da 


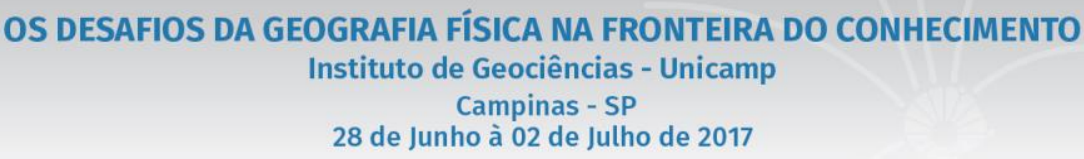

instalação de diversos projetos, alguns anteriores a criação do município, como: a empresa Jayoro (1970), a rodovia estadual AM-240 (1978), a Usina Hidrelétrica de Balbina (1989), o Projeto de Mineração do Rio Pitinga (1982) e os projetos de colonização Projeto de Assentamento (PA) Uatumã (1987), PA Canoas (1992), PA Rio Pardo (1996) e Projeto de Desenvolvimento Sustentável (PDS) Morena (2000) (OLIVEIRA, 2000; SCHWADE, 2012).

Destacado esse cenário, a ocupação antrópica se deu, principalmente, ao longo e nas cercanias, com a abertura de estradas vicinais, das rodovias BR-174 e AM-240, dando acesso as diversas comunidades rurais, dentro e fora dos assentamentos agrícolas, além dos núcleos urbanos da Sede Municipal, da Vila de Balbina e da Vila de Pitinga. Com isso, a agropecuária foi se expandindo ao longo desses eixos, avançando em forma de cultivos permanentes, cultivos temporários e pecuária (SCHWADE, 2012).

Realidade que pode ser visualizada a partir de imagens produto do sensoriamento remoto, sendo esta, a tecnologia que permite obter imagens e outros tipos de dados da superfície terrestre através da captação e do registro da energia refletida ou emitida pela superfície (FLORENZANO, 2011). Na Amazônia os estudos apoiados no uso de imagens de satélites são cada vez mais frequentes, utilizados no levantamento de desmatamento e queimadas. A confiabilidade e a rapidez no processo de sensoriamento permitem uma maior facilidade na aquisição de dados que são de grande importância para o mapeamento de uso e cobertura da terra.

No município diversos trabalhos já foram realizados, a exemplo, três dissertações que retratam diferentes temas, como: o uso do espaço, a dinâmica populacional e econômica do ambiente rural do município (SACRAMENTA, 2010; CANÃS, 2012; SCHWADE, 2012). Estudos apoiados no uso de geotecnologias também foram realizados no município, como o de MÜLLER e CARVALHO (2005) sobre o uso de produtos CBERS para o zoneamento geoambiental do município de Presidente Figueiredo, e sobre o mapeamento das alterações na paisagem da BR-174, de PINHEIRO et al (2011).

Com isso, para a realização deste trabalho foi definido como recorte espacial o município de Presidente Figueiredo, Estado do Amazonas e como recorte temporal o ano de 2011, objetivando compreender a espacialização da agropecuária no município.

\section{Matérias e Métodos}

\section{1. Área de Pesquisa}

O município de Presidente Figueiredo está localizado no nordeste do Estado do Amazonas (Figura 1). Sua sede municipal está localizada as margens da BR-174, constituindo-se como a principal via de acesso ao município. Sua área territorial é de $25.421,254 \mathrm{~km}^{2}$ e sua população, segundo estimativas do 
XVII Simpósio Brasileiro de Geografia Fisica Aplicada

I Congresso Nacional de Geografia Física

\section{OS DESAFIOS DA GEOGRAFIA FÍSICA NA FRONTEIRA DO CONHECIMENTO \\ Instituto de Geociências - Unicamp \\ Campinas - SP \\ 28 de Junho à 02 de Julho de 2017}

ano de 2016 é de 33.703 habitantes (IBGE, 2016), com uma densidade demográfica de 1,33 habitante por $\mathrm{km}^{2}$.

As atividades econômicas desenvolvidas no município são diversas, os valores do Produto Interno Bruto (PIB), referente ao ano de 2012, estão divididos em: agropecuária 280,7 milhões reais, valor que representa 52,6\% do PIB; atividades de serviços 183,6 milhões reais, 34,4\% do total produzido; atividades industriais 53,6 milhões reais, $10,1 \%$ do total produzido; e 15,9 milhões reais provenientes de impostos sobre produtos líquidos de subsídios, valor que representa 3,0\% do PIB do município; totalizando 534 milhões de reais, valor correspondente a apenas $0,8 \%$ do PIB estadual, mas que lhe rendia quarto lugar entre os municípios da Região Metropolitana de Manaus e o sétimo lugar entre as maiores economias dentre os 62 municípios do Amazonas (IBGE, 2014).

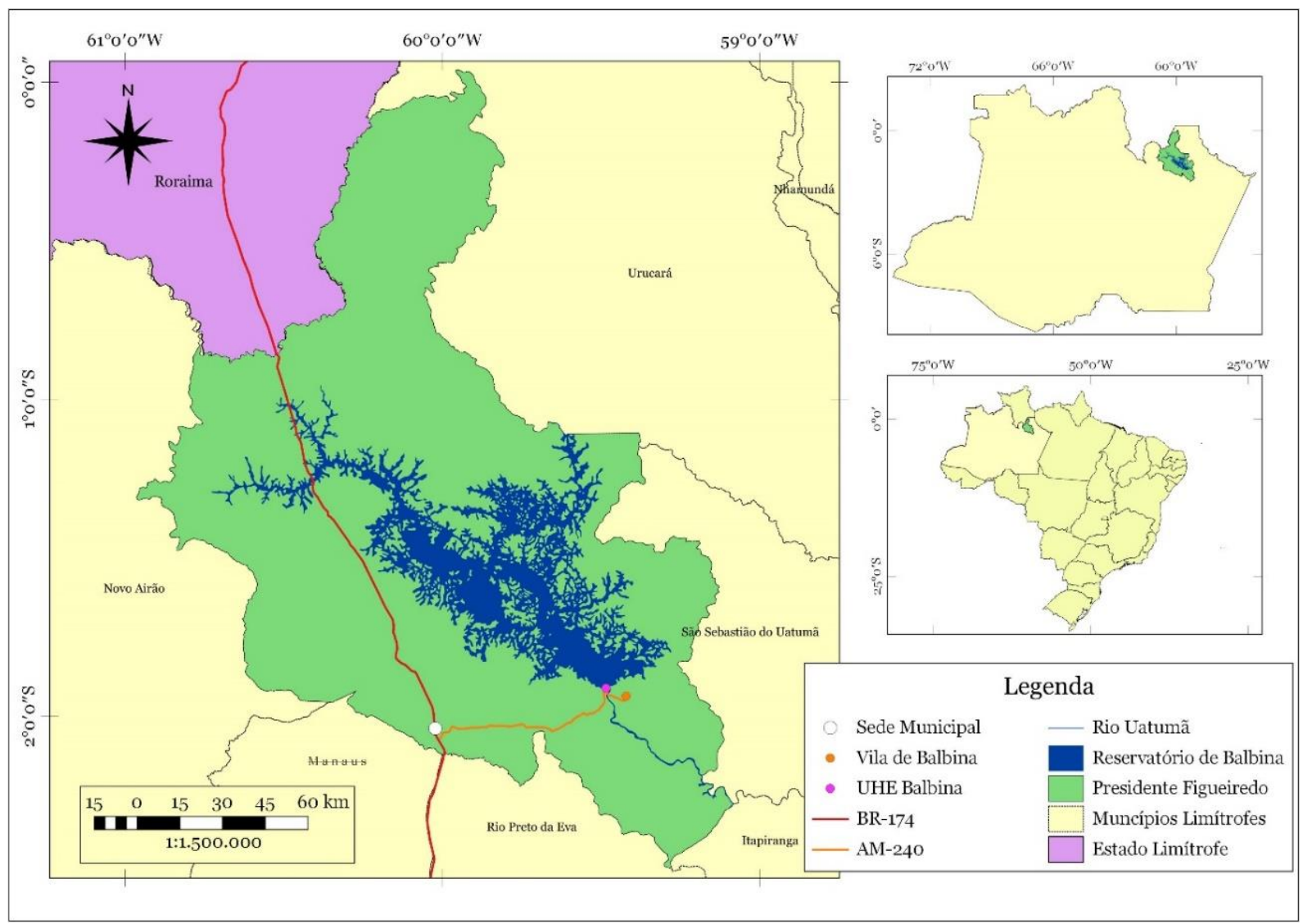

Figura 1 - Localização do município de Presidente Figueiredo

\subsection{Levantamento de dados de agropecuários}

Os dados agropecuários foram obtidos por meio do banco de dados Cidades, disponível no portal do IBGE, referentes as lavouras temporárias, as lavouras permanentes, ao efetivo de rebanho e as pastagens, relativo ao ano de 2011. Após a seleção dos dados foram geradas tabelas e gráficos, utilizando o software Microsoft EXCEL, para posterior a análise e sistematização. 
No portal do IBGE os dados referentes as pastagens só estão disponíveis no Censo Agropecuário realizado em 2006, por isso foi necessário estimar as áreas de pastagens do ano de 2011. Para isso obteve-se a densidade de bovinos, o rebanho mais numeroso dentre os de grande porte, dividiu-se o número de cabeças pela a área das pastagens em 2006, obtendo o valor de 0,72 cabeça por hectare, a partir deste valor estimou-se o tamanho das pastagens, dividindo o número de bovinos pela referida densidade.

\subsection{Elaboração do mapa de uso e cobertura da terra}

Foram utilizadas imagens do satélite Landsat $5 \mathrm{TM}$, elaborado um mosaico a partir de quatro cenas, com as seguintes orbitas-ponto e datas: 230-061, 08/08/2011; 230-062, 08/08/2011; 231-060, 31/08/2011; 231-061, 31/08/2011. Com as bandas 1, 2, 3, 4, 5 e 7, de resolução espacial de $30 \mathrm{~m}$, que facilitam a interpretação da cobertura e do uso da terra (IBGE, 2013), gerou-se uma composição RGB 543. Posteriormente foi realizada classificação supervisionada, utilizado o classificador minimum distance, gerando uma imagem temática, para a identificação das classes: água, áreas de vegetação natural e áreas antropizadas. Tais etapas foram realizadas com o auxílio do software ENVI e para a construção do layout final do mapa foi utilizado o software Qgis.

\subsection{Levantamento de dados de campo}

Os trabalhos de campo visam identificar ou confirmar as informações adquiridas previamente em gabinete, com observação e descrição da paisagem, registrado em caderneta de campo e fotografias (IBGE, 2013). Os trabalhos de campo foram realizados em quatro datas (período de 2014-2015). A averiguação dos diferentes usos agropecuário ocorreu nas proximidades da rede viária.

\section{Resultados e Discussão}

\subsection{Caracterização agropecuária}

A dinâmica espacial da agropecuária está atrelada ao cultivo de diversas culturas produtivas em lavouras permanentes e temporárias, analisadas a partir das variáveis, área destinada a colheita e área plantada; e, aos números de efetivo de rebanho de gado, analisada a partir da variável, pastagens. Estas são categorias chave para o entendimento da dinâmica agropecuária no município de Presidente Figueiredo, segundo o IBGE (2013) estas são áreas, que têm por finalidade a utilização da terra para o cultivo de alimentos, fibras, e commodities do agronegócio. 


\section{OS DESAFIOS DA GEOGRAFIA FÍSICA NA FRONTEIRA DO CONHECIMENTO \\ Instituto de Geociências - Unicamp \\ Campinas - SP \\ 28 de Junho à 02 de Julho de 2017}

\subsubsection{Culturas permanentes}

Lavouras permanentes compreendem os cultivos de ciclo vegetativo de longa duração, sendo possível manter a produção durante vários anos, sem a necessidade de novo plantio (IBGE, 2013). No município de Presidente Figueiredo destacam-se principalmente as espécies frutíferas permanentes com o cultivo de abacate, banana, guaraná, laranja, limão, tangerina, mamão e maracujá; mas há também o cultivo de espécies de frutos secos permanentes, como do coco-da-baía; e de plantas condimentares, como da pimenta-do-reino. Com exceção do guaraná que é produzido na empresa Agropecuária Jayoro, todas as outras espécies são cultivadas em pequenas propriedades.

Dentre as culturas permanentes encontradas no município de Presidente Figueiredo, valores mensurados em hectares (ha), os cultivos de banana, coco-da-baía e guaraná são os que mais se destacam em área destinada a colheita, respectivamente, ocupando as seguintes áreas, 800 ha, 600 ha e 500 ha. Os cultivos de laranja e limão, possuem uma área bastante reduzida comparadas a esses, 84 ha e 80 ha, mas superiores ao acumulado das áreas plantadas de mamão, abacate, maracujá, tangerina e pimenta do reino, que somadas alcançam apenas 47 ha.

\subsubsection{Culturas temporárias}

Lavouras temporárias compreendem os cultivos de curta e média duração, que após a produção deixam o terreno disponível para novo plantio. As culturas semipermanentes como cana-de-açúcar e mandioca se enquadram nessa categoria (IBGE, 2013). No município de Presidente Figueiredo destacam-se as espécies frutíferas temporárias, como o abacaxi e a melancia; a de cana-de-açúcar, que é produzida em grande escala, através de técnicas produtivas modernas, na empresa Agropecuária Jayoro; e as espécies de cultivos temporários diversificados, como a mandioca, o milho e o feijão que geralmente são cultivados em pequenas propriedades.

Dentre todas as culturas temporárias e permanentes cultivadas no município de Presidente Figueiredo a cana-de-açúcar e mandioca são as que ocupam as maiores áreas destinas à colheita, a cana-de-açúcar ocupava uma área de 4.050 ha, enquanto as plantações de mandioca ocupavam uma área de 2.180 ha, muito superior aos 487 ha acumulados pelas plantações de abacaxi, arroz, feijão, milho e melancia.

\subsubsection{Pastagens}

Pastagens plantadas são áreas destinadas para a criação de animais, visando a produção econômica e de subsistência, estas áreas são dedicadas ao pastoreio de gado (IBGE, 2013). No município de Presidente Figueiredo os principais usos dessas áreas são para a pecuária de animais de grande porte, com maior destaque para os bovinos e com menor destaque para os bubalinos e equinos; e para a 
pecuária de animais de médio porte, principalmente de caprinos, mas também de suínos e ovinos. Estas são as criações de maior relevância para análise de avanço ou retrocesso das pastagens.

A partir do efetivo de rebanho de gado foi possível estimar as áreas de pastagens do município. Os bovinos são a maioria entre os rebanhos, com 14,7 mil cabeças. Com os dados divulgados pelo Censo Agropecuário de 2006, estabeleceu-se a densidade de bovinos neste respectivo ano e estimado para o ano de 2011, com 20.417 hectares. Esses números são baseados apenas no rebanho bovino, pois é o rebanho mais numeroso, mas existem no município pequenos rebanho de equinos e bubalinos, também animais de grande porte que podem ter suas próprias pastagens, apesar do comum compartilhamento de pastagens por dois ou mais rebanhos de animais.

\subsection{Espacialidades da agropecuária}

Existe uma concentração de áreas antropizadas ao longo das estradas, principalmente da BR-174 e da AM-240, mas há também nos assentamentos agrícolas, na empresa Jayoro e na Vila de Pitinga (Figura 2). As áreas antrópicas são divididas em: áreas antrópicas agrícolas e áreas antrópicas não agrícolas. Estas classes confundem-se na classificação, pois possuem as mesmas cores na composição escolhida, isso mostra quanto o levantamento de campo se faz de grande valia, para estabelecer o que de fato é encontrado nessas áreas.

As culturas temporárias possuem ciclo vegetativo geralmente inferior a um ano, deixando o terreno disponível após a produção. É o caso da cana-de-açúcar, mandioca e hortaliças, incluindo cultivos em estufas. As culturas permanentes, por sua vez, possuem ciclo mais longo, o que permite colheitas sem necessidade de novo plantio, caso de espécies frutíferas, como laranjeiras, limoeiros, coqueiros e bananeiras. Inclui ainda pastagens destinadas ao pastoreio, e áreas de silvicultura e reflorestamento (IBGE, 2013).

A cana-de-açúcar é o maior cultivo em área plantada no município, cerca de 4,05 mil hectares, esta é principal matéria-prima da usina da Agropecuária Jayoro, transformando-a em açúcar e álcool. A base para a produção do açúcar e do álcool é o caldo de cana, obtido através da moagem. O processo de industrialização do açúcar e do álcool também origina outros derivados, entre eles o melaço, o bagaço e a energia elétrica que abastece a usina (JAYORO, S/d).

A empresa Jayoro ocupa uma área de 59 mil hectares, dos quais 4,5 mil hectares destinados ao plantio de cana-de-açúcar e 400 hectares para o de guaraná, segundo o site da empresa o restante é preservado de acordo com legislação ambiental. 

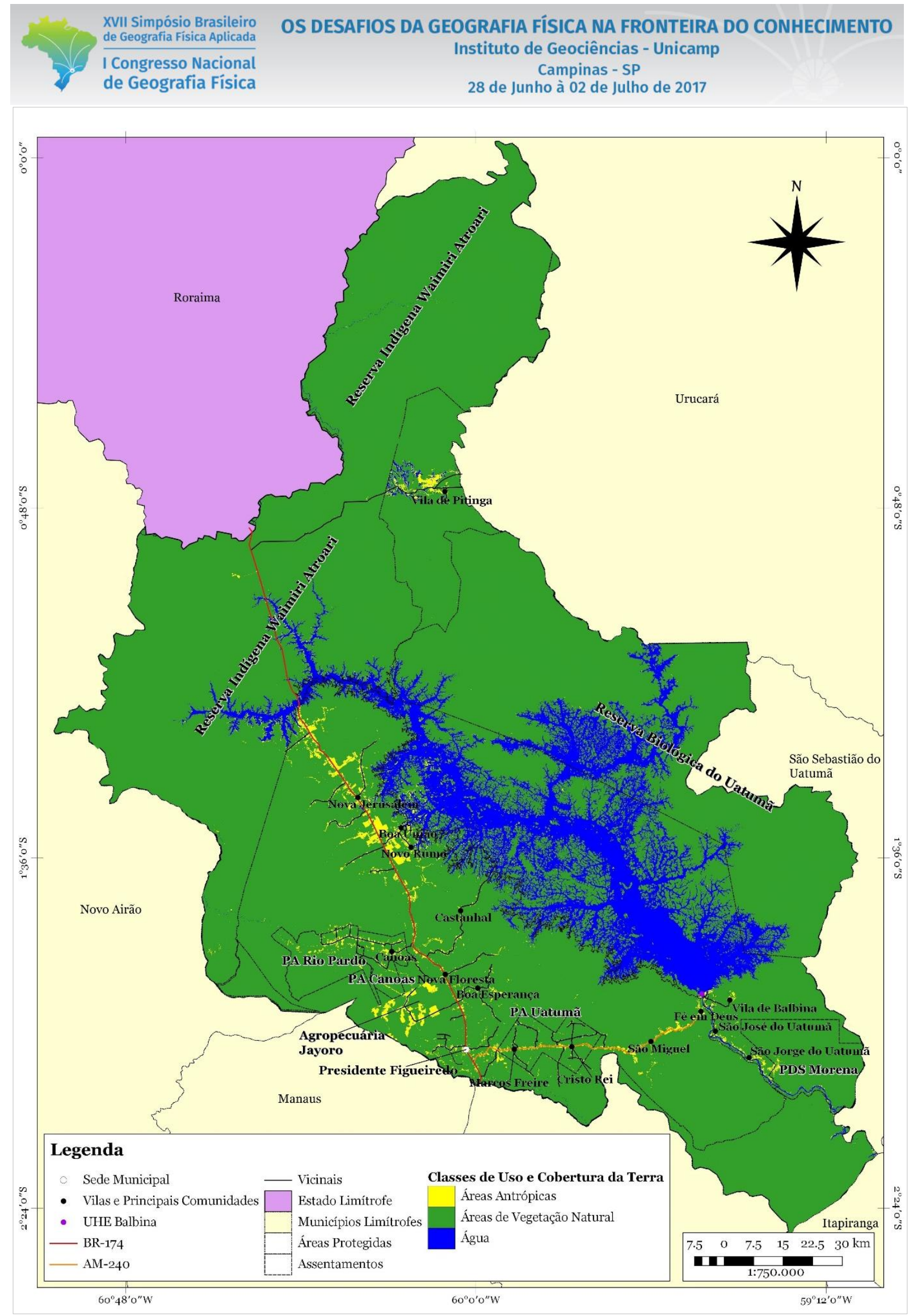

Figura 2 - Mapa de uso e cobertura da terra de Presidente Figueiredo, ano de 2011. Fonte: Imagens Landsat 5 TM, 2011. Elaborado por: João Carlos Ferreira Júnior, 2015. 


\section{OS DESAFIOS DA GEOGRAFIA FÍSICA NA FRONTEIRA DO CONHECIMENTO \\ Instituto de Geociências - Unicamp \\ Campinas - SP \\ 28 de Junho à 02 de Julho de 2017}

Apesar de produzir quase toda a cana-de-açúcar do munícipio, alguns pequenos agricultores também a cultivam, ao longo da AM-240, esta produção é comprada pelo Jayoro para depois ocorrer o beneficiamento na usina. Além da cana-de-açúcar a Jayoro também cultiva guaraná, com o aproveitamento das suas sementes transformando-as em extrato de guaraná, obtido através do beneficiamento das sementes e moagem (JAYORO, S/d). Por estar localizada em uma área de terreno plano é possível a mecanização no plantio e na colheita (Figura 3).

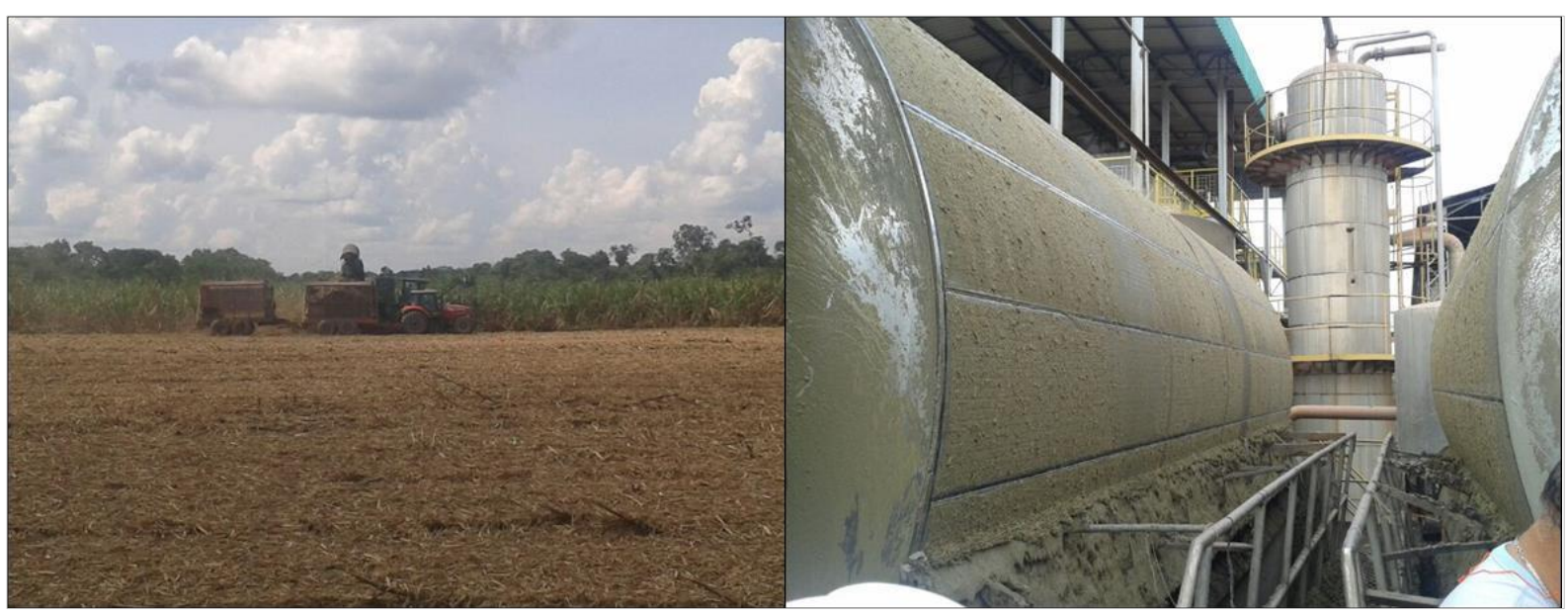

Figura 3 - Colheita e Usina de moagem de cana-de-açúcar na Agropecuária Jayoro

O segundo maior cultivo do município é mandioca. São encontradas pequenas plantações ao longo dos ramais, mas segundo feirantes do Mercado Municipal de Presidente Figueiredo, a maior parte da produção que vai para a feira, vem do Projeto de Desenvolvimento Sustentável Morena, localizado ao sul da Vila de Balbina, as margens do Rio Uatumã e das ilhas do reservatório de Balbina, são destes lugares que saem a maior parte da mandioca e de seus derivados, como farinha d'água, goma, tapioca, tucupi e pé de moleque, consumidos e comercializados na sede municipal. Esta é a cultura que melhor se adapta ao solo com poucos nutrientes e declivoso do município, sendo a primeira a ser plantada logo após o desmate e a queima da área a ser lavrada.

As plantações de coco-da-baía são encontradas principalmente na AM-240, dentro do Assentamento Uatumã. Já as plantações de banana são encontradas principalmente no Assentamento Canoas e nas ilhas do reservatório, a maior parte da produção é destinada a Manaus (Figura 4). No ramal da comunidade do Castanhal além das hortaliças, também produzem laranja e limão, seguidos por banana e coco-da-baía, é deste ramal que sai a maior parte dos produtos comercializados no Mercado Municipal do município. 


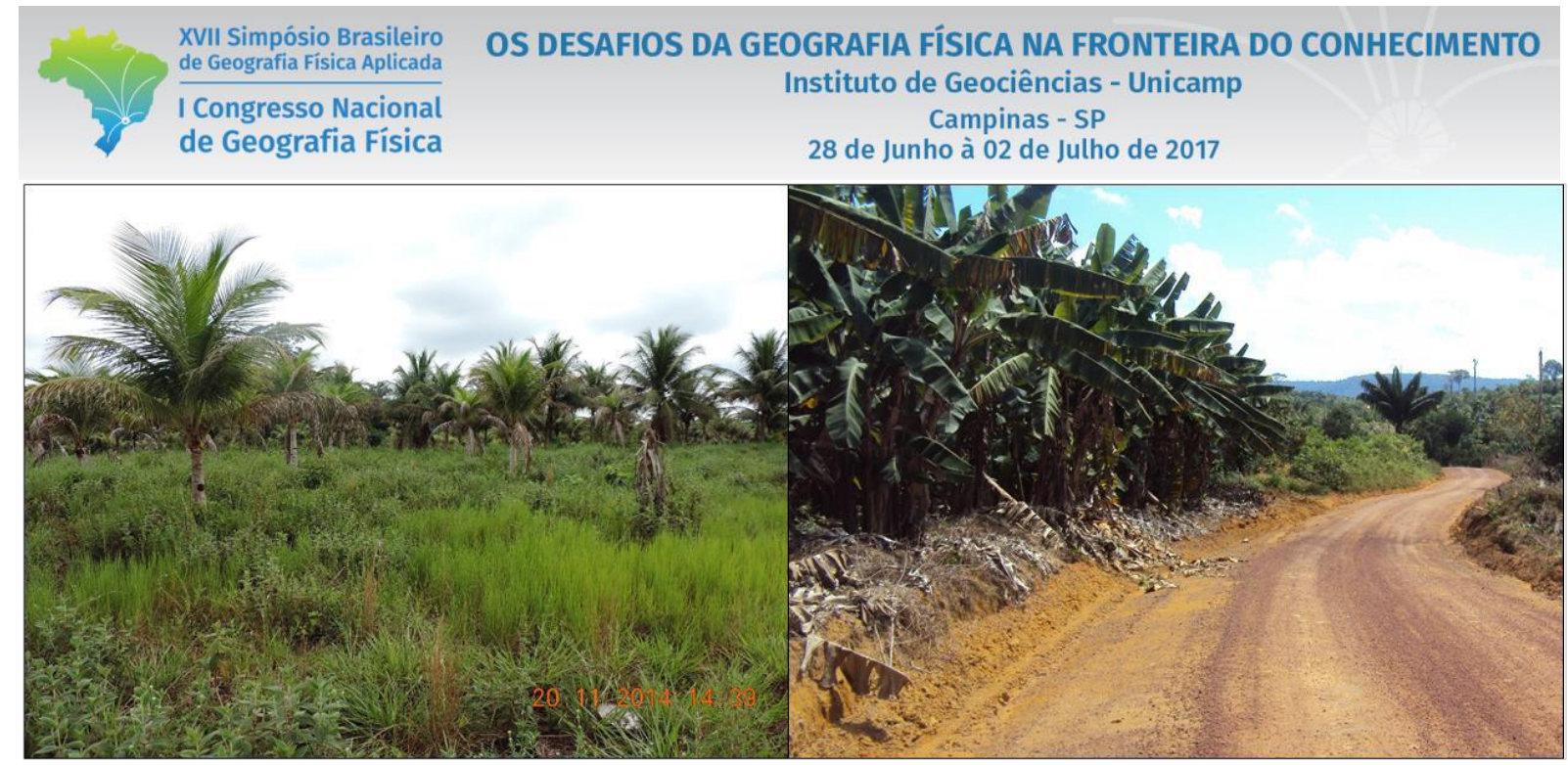

Figura 4 - Plantação de coco-da-baía, na BR-174 e plantação de banana, PA Canoas

As pastagens também fazem parte das áreas antrópicas agrícolas, estas encontram-se, sobretudo, em extensas áreas entre quilômetros 165 e 200 da BR-174, entre o ramal de acesso a comunidade Boa União e o limite da Reserva Indígena Waimiri Atroari, é possível a visualização de extensas pastagens (Figura 5), pois são áreas bastante planas. Destas propriedades é de onde sai a maior parte da carne bovina consumida no município.

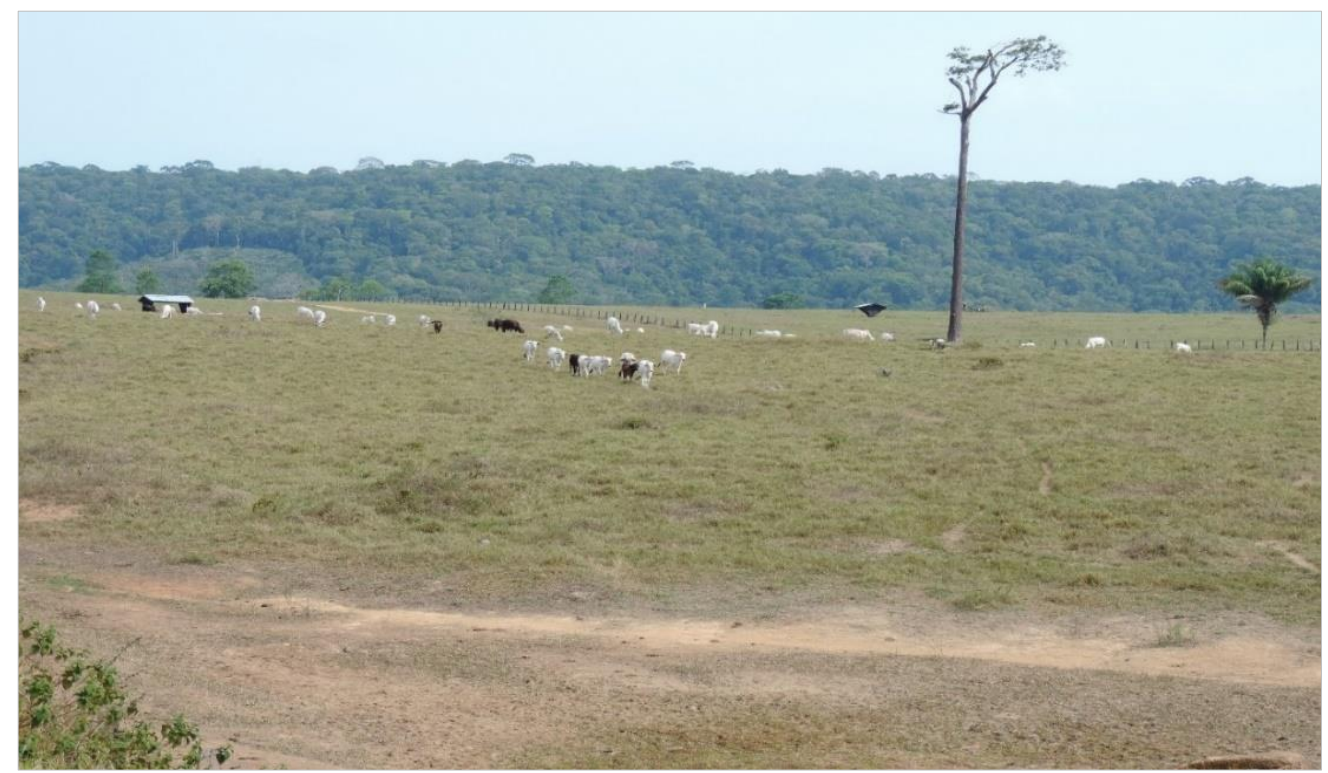

Figura 5 - Área de pastagem na BR-174, próximo a comunidade Nova Jerusalém

\section{Conclusões}

As culturas com maior destaque em área ocupada são a cana-de-açúcar e a mandioca, ambas culturas temporárias. A cana-de-açúcar possui o posto de cultura predominante, porém sua produção é concentrada pela Jayoro. A mandioca é segunda cultura em área plantada, é cultivada por pequenos agricultores que ocupam as margens das estradas e ramais, suas manufaturas têm destino certo no mercado consumidor local. De modo geral há um predomínio da agropecuária ao longo da rede viária, a áreas de pecuária concentram-se no trecho da BR-174, próximo a Reserva Indígena Waimiri Atroari. 
As culturas permanentes são comuns nos assentamentos agrícolas, principalmente, PA Canoas e PA

Uatumã. Destacando a influência desses projetos na espacialização da agropecuária do município.

\section{Agradecimentos}

Agradeço à Universidade do Estado do Amazonas (UEA) e ao Conselho Nacional de Desenvolvimento Científico (CNPq) pelo apoio estrutural e financeiro, imprescindíveis para a realização desta pesquisa.

\section{Bibliografia}

CAÑAS, A R P. A. Conflitos silenciosos: a pesca amadora no lago de Balbina, Presidente Figueiredo, Amazonas. Manaus: UFAM, 2012.

IBGE. Censo Agropecuário 2006: Brasil, Grandes Regiões e Unidades da Federação. Rio de Janeiro: IBGE, 2009.

IBGE. Manual Técnico de Uso da Terra. $3^{\circ}$ ed. Rio de Janeiro: IBGE, 2013.

IBGE. Presidente Figueiredo: Informações Completas. Portal do IBGE, 2016. Disponível em: *$<$ http://www.cidades.ibge.gov.br/xtras/perfil.php?lang=\&codmun=130353\&search=amazonas/presidentefigueiredo>. Acesso em: novembro de 2016.

IBGE. Produto Interno Bruto dos Municípios 2012. IBGE, 2014.

JAYORO. Produtos. S/d. Disponível em: <http://www.jayoro.com.br/produtos/index.shtml >. Acessado em: novembro de 2016.

MULLER, A. J.; CARVALHO, A. S. Uso de Produtos CBERS para o Zoneamento Geoambiental de Presidente Figueiredo, no Amazonas. In: XII Simpósio Brasileiro de Sensoriamento Remoto, 2005, Goiânia: Anais do XII Simpósio Brasileiro de Sensoriamento Remoto, 2005.

OLIVEIRA, J. A. Cidades na Selva. Manaus: Valer, 2000.

PINHEIRO, E. da S.; RODRIGUES, E. P.; OLIVEIRA, M. S. de. Uso De Geotecnologias para o Mapeamento das Alterações na Paisagem da Rodovia Br-174. Boa Vista: Revista Geográfica Acadêmica, 2011.

SACRAMENTA, D. M. O. "Lugares que migram" as imagens do mundo vivido pelos assentados do Canoas em Presidente Figueiredo (AM). Manaus: UFAM, 2010.

SAIKO, É. A. Caracterização de trajetórias de padrões de ocupação humana Amazônia Legal por meio de mineração de dados. São José dos Campos: INPE, 2011.

SCHWADE, T. M. M. Reordenamento territorial e conflitos agrários em Presidente Figueiredo Amazonas. Manaus: Universidade Federal do Amazonas, 2012. 